\title{
Mekanik Ventilasyon Uygulanan Akut Solunum Yetmezlikli Hastalarda Nöromüsküler Blokajın Oksijen ve Enerji Tüketimine Etkisi
}

\author{
The Effect of Neuromuscular Blockade on Oxygen Consumption and Energy \\ Expenditure in Mechanically Ventilated Acute Respiratory Insufficiency Patients
}

\author{
Esra Yüksel, Illkin Çankayalı, Kubilay Demirağ, Ali Reşat Moral \\ Ege Üniversitesi Tıp Fakültesi, Anesteziyoloji ve Reanimasyon Anabilim Dalı, Izmir, Türkiye
}

\section{ÖZET}

Amaç: Bu çalışmanın amacı akut solunum yetmezliği tanılı mekanik ventilatör desteği altında sedatize izlenen hastalarda nöromüsküler blokajın oksijen ve enerji tüketimi üzerindeki etkisini araștırmaktır. Gereç ve Yöntem: Akut solunum yetmezliği tanısı ile mekanik ventilasyon desteği uygulanan 21 hasta çalışmaya dahil edildi. Bütün hastalara Ramsay sedasyon skalası 3 olacak sekilde propofol infüzyonu uygulandı.Yeterli sedasyon ve hemodinamik stabilitenin sağlanmasının ardından tüm hastaların oksijen tüketimi, karbondioksit üretimi ve enerii tüketimine ait bazal değerler indirekt kalorimetri cihazı ile ölçüldü ve kaydedildi. Nöromüsküler ileti TOF-Guard ile monitörize edildikten sonra hastalara $0,1 \mathrm{mg} / \mathrm{kg}$ bolus doz vekuronyum uygulandı. Oksijen, karbondioksit ve enerji tüketimi değerleri TOF 0, 25, 50, 90 olduğunda indirekt kalorimetri cihazı ile ölçülerek kaydedildi.

Bulgular: Hastaların kürarizasyon öncesi ve sonrası hemodinamik parametreleri, ventilasyon parametreleri, arteriyel kan gazı değerleri arasında istatistiksel olarak anlamlı bir fark saptanmadı ( $p>0,05)$. Kürarizasyon öncesi (bazal değer) ve TOF 0 iken ölçülen oksijen tüketimi, karbondioksit üretimi ve enerji tüketimi değerleri arasında istatistiksel olarak anlamlı bir azalma gözlendi $(p<0,05)$. Ancak TOF 25, 50, 90 değerlerleri ile bazal değer arasında anlamlı bir değişiklik saptanmadı $(p>0,05)$

Sonuç: Yoğun bakımda hastaların günlük enerji gereksinimi hesaplanırken TOF 0 düzeyinde kürarize olan hastalarda nöromüsküler blokajin enerji ve oksijen tüketimini azaltıcı etkisinin göz önünde bulundurulması gerektiği sonucuna varıldı. (Türk Yoğun Bakım Derneği Dergisi 2012; 10: 8-12)

Anahtar Kelimeler: Yoğun bakım, nöromüsküler blokaj, enerji tüketimi, oksijen tüketimi

\section{SUMMARY}

Objective: The aim of this study is to investigate the effect of neuromuscular blockade on oxygen consumption and energy expenditure in sedated patients with acute respiratory failure who were followed under mechanical ventilation support.

Material and Method: 21 acute respiratory failure patients under mechanical ventilation support were included in the study. All patients were sedated with propofol infusion to have a sedation level of 3 on the Ramsay scale. After adequate sedation and hemodynamic stability was achieved, baseline values of oxygen consumption, carbondioxide production and energy consumption of the patients were measured by indirect calorimetry device and recorded. Neuromuscular transmission was monitorized by TOF-Guard, and then $0,1 \mathrm{mg} / \mathrm{kg}$ bolus dose vecuronium was administered to the patients. When TOF $0,25,50,90$ values were obtained, oxygen, carbondioxide and energy consumption were measured by indirect calorimetry device and recorded.

Results: No statistically significant difference were found between preand post-curarisation hemodynamic parameters, ventilation parameters, arterial blood gas values $(p>0.05)$. A statistically significant decrease was observed between the oxygen consumption, carbondioxide production and energy consumption measured before curarisation and when TOF value was $0(p<0.05)$. However, there was no significant difference between TOF 25, 50, 90 values and the baseline value $(p>0.05)$.

Conclusion: It was concluded that the effect of neuromuscular blockage on reducing energy and oxygen consumption should be taken into consideration while calculating the daily energy need in intensive care in patients curarized at TOF 0 level. (Journal of the Turkish Society Intensive Care 2012; 10: 8-12)

Key Words: Intensive care, neuromuscular block, energy expenditure, oxygen consumption

Yazışma Adresi/Address for Correspondence: Dr. Esra Yüksel, Ege Üniversitesi Tıp Fakültesi, Anesteziyoloji ve Reanimasyon Anabilim Dall, Izmir, Türkiye Tel.: +90 2323902141 E-posta: esrayuksel73@yahoo.com Geliș Tarihi/Received: 24.10.2011 Kabul Tarihi/Accepted: 06.01.2012 


\section{Giriş}

Organizmada metabolizmanın ve yaşamsal fonksiyonların sürdürülebilmesi için oksijen sunumunun devamlılığı gereklidir (1). Akut solunum yetmezliği, solunum işlevine katılan organların bir veya birkaçının fonksiyon bozukluğu sonucunda gelişen, pulmoner kapiller yataktan oksijenin dolaşım sistemine dağılması ve/veya karbondioksitin atılmasında bozuklukla kendini gösteren bir durumdur (2).Yoğun bakım hastalarında akut solunum yetmezliği sıklıkla mekanik ventilasyon desteği gerektirir. Mekanik ventilasyonla ortaya çıkan asenkroniyi elimine etmek için ise sedatif ve nöromüsküler bloker (NMB) ilaçlar kullanılmaktadır (3). Sedatif ajanların oksijen tüketimi (VO2) ve enerji tüketimi (ET) üzerine etkisi ile ilgili daha ayrıntılı çalışmalar olmakla bereber $(4,5)$ NMB ile ilgili çalışmalar az sayıda ve çelişkilidir (6).

Yoğun bakımda yatan hastaların günlük enerji gereksinimleri belirlenirken hastaların günlük ET'ni gösteren tahmini formüller [Harris Benedict (HB)Denklemi, Schofield Formülü] veya indirekt kalorimetre yönteminden yararlanılmaktadır. Indirekt kalorimetre enerji ihtiyacının saptanmasında en hassas yöntemdir (7).

Biz de çalışmamızda akut solunum yetmezliği tanısıyla mekanik ventilatör desteğinde sedatize olarak izlenen hastalarda NMB'in VO2 ve ET üzerine etkilerini indirekt kalorimetri yöntemi ile incelemeyi amaçladık.

\section{Gereç ve Yöntem}

Çalışmamız Ege Üniversitesi Tıp Fakültesi Anesteziyoloji ve Reanimasyon Anabilim Dalı Yoğun Bakımında hastane etik kurul onayı ve hasta yakınlarının onamı alındıktan sonra gerçekleştirilmiştir.

Çalışmaya dahil edilme kriterleri:

- 18-65 yaş arası

- Bilinç açık

- Parsiyel arteriyel oksijen basıncı $\left(\mathrm{PaO}_{2}\right) /$ inspire edilen oksijen fraksiyonu $\left(\mathrm{FiO}_{2}\right)<250 \mathrm{mmHg}$

-Politravma ön tanısı ile hastaneye yatırılıp akut solunum yetmezliği nedeniyle yoğun bakımda mekanik ventilasyon desteğine alınan mekanik ventilasyonla uyumsuzluk nedeniyle önce sedatize, daha sonra tek doz kürarize edilen hastalar

\section{Çalışmadan çıkarma kriterleri:}

Hipertermi $\left(>38^{\circ} \mathrm{C}\right)$, hipotermi $\left(<35^{\circ} \mathrm{C}\right), \mathrm{FiO}_{2}$ 'nun \%60'ın üzerinde olması, ajitasyon, konvülziyon, intoksikasyon, metabolik ve hemodinamik instabilizasyon, kafa travması (GKS<8), karaciğer yetmezliği, böbrek yetmezliği, diabetes mellitus tanısı olan hastalar çalışmaya dahil edilmedi.
Hastalar basınç destekli modda (PS) ventilasyon parametreleri 6-7 ml/kg tidal volum, 14-16/dk solunum frekansı, $\mathrm{PaO}_{2}>60 \mathrm{mmHg}$, parsiyel arteriyel karbondioksit $\left(\mathrm{PaCO}_{2}\right)$ değeri 35-45 mmHg olacak, $\mathrm{FiO}_{2}$ değeri \%60 üzerinde olmayacak şekilde Servo $90^{\circ} \mathrm{C}$ (SiemensSweden) cihazı ile mekanik ventilasyon desteğine alındı. Maksimum hava yolu basıncının $30 \mathrm{cmH}_{2} \mathrm{O}^{\prime} \mathrm{yu}$ geçmemesine dikkat edildi. Mekanik ventilatör ile uyumsuzluğu nedeniyle çalışma sonlanana kadar Ramsay sedasyon skalası (8) 3 olacak şekilde propofol infüzyonu ile sedasyon uygulandı. Politravma hasta grubu olması nedeniyle opioid ajanlarla analjezi sağlandı.

Tüm hastaların günlük kalori ihtiyaçları HB formülü kullanılarak hesaplandı. Hesaplanan kalori çalışma süresince sabit tutularak enteral yoldan hastalara verildi. Yeterli sedasyon ve hemodinamik stabilitenin sağlanmasını takiben tüm hastalara Deltatrac \| metabolik monitor (Deltatrac II, Datex-Ohmeda Instrumentarium Corp., Helsinki, Finland) bağlandı ve 30 dakika süren ısınma süresini takiben cihaz kalibre edildi.

Indirekt Kalorimetri: Klinisyenin VO2 ve karbondioksit tüketimi $\left(\mathrm{VCO}_{2}\right)$ ölçümlerinden ET'ni tahmin etmesine olanak sağlamaktadır. Indirekt kalorimetri enerji tüketimini Weir eşitliğinden faydalanarak hesaplar (9).

Weir eşitliği: ET (kcal/gün) = 3,941 Von (L/gün) + 1,106 $\mathrm{VCO}_{2}$ (L/gün) - 2,17 ldrarda N (g/gün)

Protein metabolizmasını göz önüne alan denklemlerde idrar azot miktarının hesaba katılmasının sonucu çok fazla etkilemediği görülmüştür. Bu nedenle uygulaması daha kolay modifiye eşitlikler geliştirilmiştir (10).

Modifiye Weir denklemi: $\mathrm{ET}=\left[3,9\left(\mathrm{VO}_{2}\right)+1.1\left(\mathrm{VCO}_{2}\right)\right]^{*} 1,44$

Cihaz kalibrasyonu sonrası hastalar sedatize,spontan solunumda PS modunda mekanik ventilatör desteğinde iken ilk ölçüm bazal değer olarak kaydedildi. Vekuronyum uygulamasından önce periferik sinir stimülatörü olan ve akseloremetrik yöntem uygulayan TOF-Guard cihazı (Organon Teknika NV, 2300 Turnhout, Belgium) ile monitörizasyona ilişkin hazırlıklar tamamlandı. Ulnar sinir trasesi boyunca ve el bileği cilt kıvrımının 0,5-1 cm proksimaline $30 \mathrm{~mm}$ çaplı yüzeyel bir elektrod (Bio-flex, Biometer International A/S Odense NV, Denmark) ve bu elektrodun da 2-3 cm proksimaline, aynı özelliklere sahip ikinci bir elektrod yerleştirildi. Elektrodların yerleştirilmesini takiben, TOF-Guard cihazına ait stimülasyon kabloları elektrodlara bağlandı. Akselerasyon transdüseri başparmağın interfalangeal ekleminin volar yüzüne, ISI sensörü ise tenar eminensia üzerine yerleştirildi.

Cihazla uyumsuzluğun devamında tek doz 0,1 mg/kg vekuronyum uygulandı. Kürarizasyon sonrasında, ventilasyon parametreleri 6-7 ml/kg tidal volum, 14-16/dk solunum 
Tablo 1. Hastaların demografik verileri (ortalama \pm SD)

\section{Olgu sayısı}

Yaş (yıl)

21

Ağırlık (kg)

$52,43 \pm 20,4$

Boy $(\mathrm{cm})$

$73,57 \pm 10,39$

APACHE II skoru

$172,38 \pm 6,82$

$\mathrm{HB}$ (kcal/gün)

$10,76 \pm 5,73$

$1946 \pm 457$

APACHE skoru:' Acute Physiology and Chronic Health Evaluation' skor

HB: Harris-Benedict

\begin{tabular}{|c|c|c|}
\hline & KÖ & KS \\
\hline $\mathrm{FiO}_{2}$ & $0,36 \pm 0,07$ & $0,37 \pm 0,07$ \\
\hline Tidal hacim (ml) & $464 \pm 118$ & $548 \pm 92$ \\
\hline Frekans (solunum/dk) & $18 \pm 6,6$ & $15 \pm 2$ \\
\hline PEEP $\left(\mathrm{cmH}_{2} \mathrm{O}\right)$ & $3,7 \pm 2,1$ & $3,6 \pm 2$ \\
\hline
\end{tabular}

$\mathrm{FiO}_{2}$ : Fraksiyone inspiratuar oksijen konsantrasyonu

PEEP: Positive End-Ekspiratory Pressure

Tablo 3. Hastaların kürarizasyon öncesi (KÖ) ve sonrası (KS) arteriel kan gazı değerleri (ortalama \pm SD)

\begin{tabular}{lcc} 
& KÖ & KS \\
\hline $\mathrm{Ph}$ & $7,43 \pm 0,06$ & $7,43 \pm 0,04$ \\
$\mathrm{PaO}_{2}(\mathrm{mmHg})$ & $89 \pm 20$ & $86 \pm 22$ \\
$\mathrm{PaCO}_{2}(\mathrm{mmHg})$ & $39 \pm 4,6$ & $39 \pm 6,5$ \\
$\mathrm{HCO}_{3}(\mathrm{mmol} / \mathrm{L})$ & $26,7 \pm 4,6$ & $26,5 \pm 4$ \\
$\mathrm{BE}$ & $3,2 \pm 4,9$ & $2,8 \pm 4,3$ \\
$\mathrm{O}_{2}$ saturasyonu (\%) & $96,4 \pm 2,6$ & $95,6 \pm 2,5$ \\
\hline $\mathrm{PaO}_{2}:$ parsiyel arteriyel oksijen basıncı & \\
$\mathrm{PaCO}_{2}:$ parsiyel arteriyel karbondioksit basıncı & \\
$\mathrm{HCO}_{3}$ : bikarbonat & \\
$\mathrm{BE}^{\text {baz açı̆ı }}$ & \\
\hline
\end{tabular}

Tablo 4. Hastaların kürarizasyon öncesi (KÖ) ve sonrası (KS) hemodinamik parametreleri (ortalama \pm SD)

KÖ KS

\begin{tabular}{lcc}
\hline $\mathrm{SAB}(\mathrm{mmHg})$ & $121,4 \pm 17,5$ & $116,3 \pm 26,6$ \\
$\mathrm{DAB}(\mathrm{mmHg})$ & $61 \pm 11,4$ & $57 \pm 11,8$ \\
$\mathrm{OAB}(\mathrm{mmHg})$ & $76,4 \pm 12$ & $75,3 \pm 15$ \\
$\mathrm{KAH}($ atım $/$ dakika $)$ & $105,7 \pm 17$ & $105 \pm 21$ \\
$\mathrm{SVB}\left(\mathrm{cmH}_{2} \mathrm{O}\right)$ & $6,2 \pm 2,6$ & $6,3 \pm 2,7$ \\
\hline
\end{tabular}

SAB:Sistolik arter basınc।

DAB:Diastolik arter basınc।

OAB:Ortalama arter basınc

KAH:Kalp atım hızı

SVB:Santral ven basıncı frekansı, $\quad \mathrm{PaO}_{2}>60 \mathrm{mmHg}, \quad \mathrm{PaCO}_{2}$ değeri $35-45 \mathrm{mmHg}$ olacak, $\mathrm{FiO}_{2}$ değeri \%60 üzerinde olmayacak şekilde basınç kontrollu ventilasyon (PC) moduna geçildi.

Hastaların kürarizasyon öncesi (KÖ) ve sonrası (KS) arteriel kan gazı değerleri, ventilasyon parametreleri ve hemodinamik değerleri [sistolik $(S A B)$, diastolik (DAB) ve ortalama (OAB) arter basıncı, kalp atım hızı (KAH), santral ven basıncı (SVP)] kaydedildi.

Hastaların tam kas gevşemesi TOF-Guard ile doğrulandıktan sonra TOF 0, 25, 50, 90 olduğunda indirek kalorimetri ölçümleri sonucunda elde edilen $\mathrm{VO}_{2}, \mathrm{VCO}_{2}$ ve $\mathrm{ET}$ değerleri kaydedildi. Hastalara dekürarizasyon uygulanmadı.

Hastaların hiçbirinde polinöromyopati, diyafragmatik ve interkostal kas atrofisi, paralitik ileus gelişmedi.

Elde edilen veriler paired-t test ile değerlendirildi. $p<0,05$ olan değerler anlamlı kabul edildi.

\section{Bulgular}

Çalışmamıza yaşları 18-65 yaşları arasında 4'ü kadın 21 hasta dahil edilmiştir.Çalışmamızda yer alan hastaların demografik verileri (yaş, vücut ağırlı̆ı, boy, APACHE II ve III skorları, HB formülü ile hesaplanan günlük kalori ihtiyacı) Tablo 1'de gösterilmiştir.

Hastaların KÖ ve KS ventilasyon parametrelerinde (Tablo 2), arteriyel kan gazı değerlerinde (Tablo 3) ve hemodinamik değerlerinde (SAB, DAB, OAB, KAH, SVP) (Tablo 4) istatistiksel anlamlı fark saptanmamıştır $(p>0,05)$.

KÖ ve TOF-Guard monitörizasyonu ile TOF 0, 25,50 ve 90 iken ölçülen VO2,VCO2, ET değerleri Tablo 5 'da gösterilmiştir.

$\mathrm{KÖ}$ ölçülen $\mathrm{VO}_{2}$ (Grafik 1), $\mathrm{VCO}_{2}$ (Grafik 2), ET (Grafik 3) değerleri ile TOF 0 iken ölçülen değerler arasında istatistiksel olarak anlamlı bir azalma saptanmıştır $(p<0,05)$. Ancak $\mathrm{KÖ} \mathrm{VO}_{2}, \mathrm{VCO}_{2}$, ET değerleri ile TOF 25, 50, 90 olduğundaki değerler arasında anlamlı bir değişiklik saptanmamıştır $(p>0,05)$.

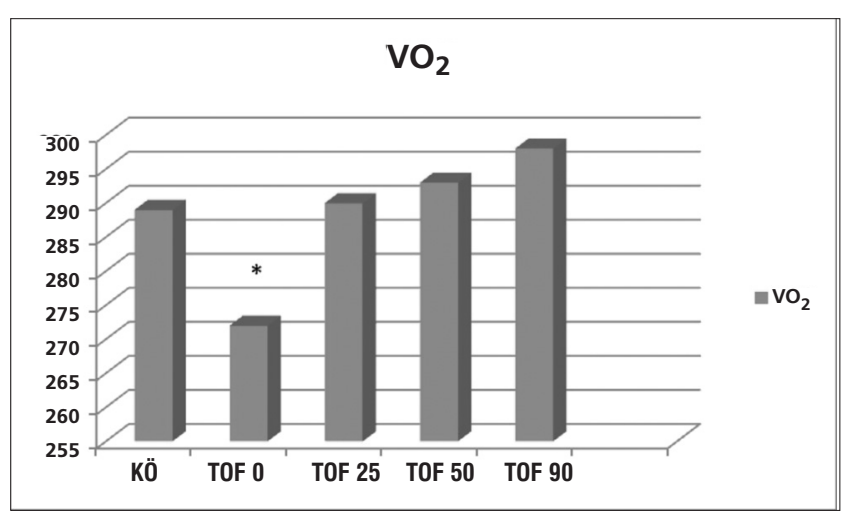

Grafik 1. Kürarizasyon öncesi ölçülen $V_{2}$ Değerleri 


\section{Tartışma}

Yoğun bakımda metabolik stres altındaki hastalarda protein-enerji malnütrisyonunun önlenmesi için enerji ve protein gereksinimlerinin karşılanması gereklidir. Hem yetersiz hem de aşırı beslenmeden kaçınılması için günlük enerji gereksiniminin hassas olarak belirlenmesi gerekmektedir.

Yoğun bakımda sıklıkla kullanılan NMB ajanların VO2 ve ET üzerine etkilerini araştıran çalışmalarda çelişkili sonuçlar elde edilmiştir. $\mathrm{NMB}$ ajanların $\mathrm{ET}$ ve $\mathrm{VO}_{2}$ üzerine etkisini indirekt kalorimetri yöntemi kullanarak araştıran bir çalışmada pediatrik yoğun bakımda mekanik ventilatör desteğinde 20 hasta çalışmaya alınmıştır (11). Midazolam ve/veya fentanil ile sedatize izlenen hastalarda NMB

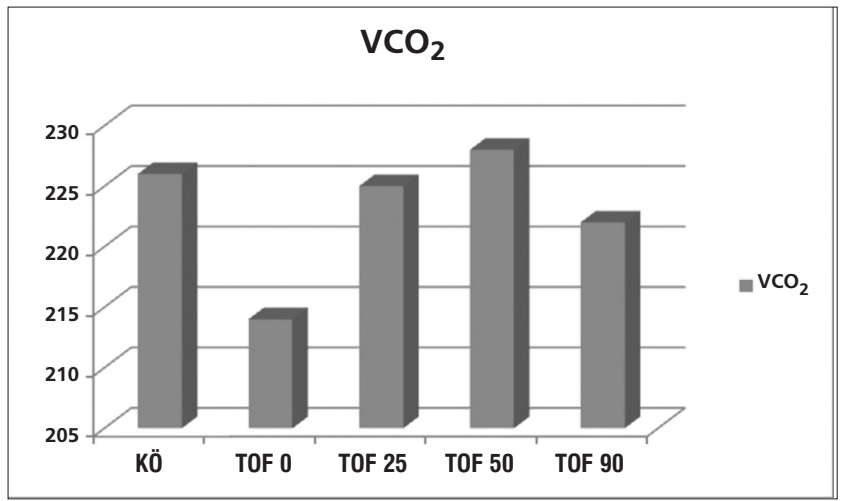

Grafik 2. Kürarizasyon öncesi ölçülen $\mathrm{V}_{\mathrm{CO}}$ değerleri

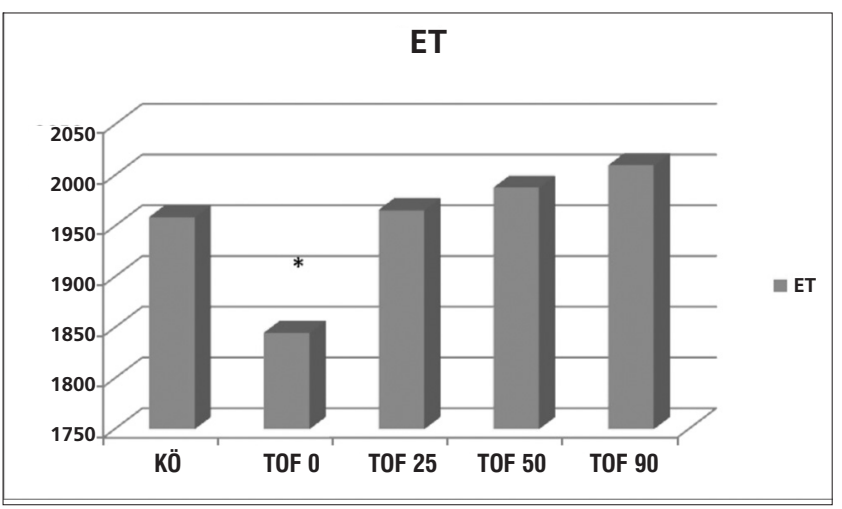

Grafik 3. Kürarizasyon öncesi ölçülen et değerleri uygulanmasından sonra VO2'de \%8,7, ET'de \%10,3'lük $(p<0,05)$ bir azalma saptanmıştır. Bizim çalışmamızda da KÖ değerlere göre KS TOF 0 iken ölçülen VO2, VCO2 ve ET değerlerinde istatistiksel olarak anlamlı bir azalma gözlenmiştir. Ancak TOF 25, 50 ve 90 değerleri ile KÖ arasında anlamlı bir değişiklik saptanmamıştır.

Marik ve ark (12) sepsis ve solunum yetmezliği tanısıyla yoğun bakımda mekanik ventilasyon desteğinde izledikleri 8 hastayı KÖ lorazepam ve morfin sulfat ile sedatize etmișlerdir. Doksakuryum ile kürarize edilen hastalarda $\mathrm{KS} \mathrm{VO}_{2}$

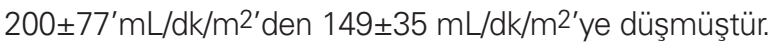

Deneysel bir çalışmada da, alfa-chlorase ile sedatize edilmiş 9 köpeğe NMB uygulanması $\mathrm{VO}_{2}$ 'ni anlamlı ölçüde $(\% 4,3)$ azaltmıştır.

Manthous ve ark (13) yoğun bakımda mekanik ventilasyon desteği altında izlenen 8 hastanın farklı ventilasyon modlarındaki $\mathrm{VO}_{2}$ değerlerini karşılaştırdıkları çalışmada kürarize edilip kontrol modunda izlenen hastaların asiste moddaki hastalara göre $\mathrm{VO}_{2}$ değerinde \%20 oranında anlamlı bir azalma saptamışlardır.

Literatürde NMB ajanların $V_{2}$ ve $E T^{\prime}$ de azalma sağladığını gösteren çalışmaların yanısıra bu etkinin gözlenmediği bazı çalışmalar da mevcuttur. Mekanik ventilasyon uygulanan ve yüksek oksijen gereksinimi bulunan 20 hasta Ramsay sedasyon skoru 5 olacak şekilde sedatize edildikten sonra atrakuryum ile kürarize edilmiştir (14). Tüm hastalarda paralizinin derecesi periferik sinir stimülatörü kullanılarak değerlendirilmiştir. Kürarizasyon öncesi T0, tam kürarize olduğu an T1, kürarizasyon sonrası T2 olarak adlandırımıştır. $\mathrm{VO}_{2}$ değerinde T1'de T0 ve T2'ye göre \%3,1 oranında istatistiksel olarak anlamlı olmayan bir düşme saptanmıştır. Yoğun bakım hastalarında ET'ni araştıran çalışmalarda sedasyonun etkisine de dikkat çekilmiştir. Sadece sedasyonun ET'ni anlamlı derecede azalttığını gösteren çalışmalar bildirilmiştir $(4,15,16)$. Swinamer ve ark (16), mekanik ventilator desteğindeki nontravmatik 7 hastada morfin ile uygulanan sedasyonun ET'ni her hastada ortalama \%8 oranında azalttığını bulmuşlardır. Gebera ve ark (17) konjenital kalp hastalığı nedeni ile opere edilen 26 çocuk hastada NMB'ın ET'ni değiştirmediğini

Tablo 5. Hastaların kürarizasyon öncesi (KÖ) ve sonrası (KS) VO 2 (Oksijen tüketimi), VCO2 (Karbondioksit tüketimi), ET (Enerji tüketimi) değerleri (ortalama \pm SD)

\begin{tabular}{lccccc} 
& KÖ & TOF0 & TOF25 & TOF50 & TOF90 \\
\hline $\mathrm{VO}_{2}\left(\mathrm{ml} / \mathrm{dk} / \mathrm{m}^{2}\right)$ & $289,0 \pm 87,4$ & $272,4 \pm 81,7^{*}$ & $290,0 \pm 88,3$ & $293,2 \pm 92,3$ & $298,5 \pm 93,7$ \\
$\mathrm{VCO}\left(\mathrm{ml} / \mathrm{dk} / \mathrm{m}^{2}\right)$ & $226,0 \pm 74,6$ & $214,5 \pm 67,0^{*}$ & $225,9 \pm 65,2$ & $228,3 \pm 73,6$ & $222,0 \pm 78,7$ \\
$\mathrm{ET}(\mathrm{kcal} / \mathrm{gün})$ & $1959 \pm 603,3$ & $1845,7 \pm 555,8^{*}$ & $1966,6 \pm 594,9$ & $1988,1 \pm 626,9$ & $2010,9 \pm 633,5$ \\
\hline${ }^{*} \mathrm{p}<0,05$ (KÖ değer ile karş̧laştırldı̆̆ında) & & & &
\end{tabular}


göstermişlerdir. Bu çalışmada çocukların derin düzeyde sedatize edildiği ve derin sedasyon altında NMB ajanların $\mathrm{VO}_{2}$ ve ET üzerine etkisinin değişebileceği bildirilmiştir. Çalışmamızda sedasyonun sonuçları etkilememesi için her hastada sedasyon düzeyi Ramsey skorlamasına göre 3 olacak şekilde sabit tutulmuştur. Bu nedenle TOF 0 zamanında $\mathrm{VO}_{2}$ ve ET değerindeki anlamlı azalmanın sadece NMB'lere bağlı olduğu düşünülmüştür.

Freebairn ve ark. (3) solunum yetmezliği nedeniyle mekanik ventilatör desteğine alınan septik şok tablosundaki 18 hastada yaptıkları çalışmada midazolam ile sedatize edilen hastalara vekuronyum uygulanması sonrası $\mathrm{VO}_{2}$ değerinde azalma saptamamışlardır. Bruder ve ark (4) da kafa travmalı 24 hasta ile yaptıkları bir çalışmada sedatize hastalarda kürarizasyon sonrası yapılan ölçümlerde ET'nin bazal değere göre \%22 oranında arttı̆̆ını göstermişlerdir. Bu ölçümlerin 119'unun 103'ü hastalar septik tablodayken yapılmıştır. Bir başka çalışmada (15) NMB ajan uygulanan 24 hasta çalışmaya dahil edilmiştir. Çalışmanın sonucunda NMB ajanların ET ve $V_{2}$ değerinde azaltıcı etkisi gözlenmemiştir. Bu hasta grubunda vücut ısısının etkisi de araştırıldığı için yüksek ateşin sonucu değiştirdiği düşünülmüştür. Bizim çalışmamızda septik şok tanısı ve yüksek ateş dışlanma kriteri olduğu için çalışmamızın sonuçları etkilenmemiştir.

Çalışmamızda yoğun bakımda mekanik ventilatör desteğinde sedatize edilen hastalarda nöromuskuler monitörizasyonla yapılan ölçümlerde sadece TOF 0 zamanında $E T$ ve $\mathrm{VO}_{2}$ değerinde anlamlı düşme saptanması bu etkinin sadece tam NMB sırasında ortaya çıktığını göstermektedir. Bu sonuca göre tam NMB sağlanan uzun süreli mekanik ventilasyon desteğindeki hastalarda günlük enerji gereksinimi belirlenirken bu azalmanın dikkate alınması kanaatine varılmıştır.

\section{Kaynaklar}

1. Shoemaker WC, Appel PL.Krom HB. Haemodynamic and oxygen transport responses in survivors and non survivors of high risk surgery. Crit Care Med 1993;21:977-90.

2. Greene KE, Peters JI. Pathophysiology of acute respiratory failure. Clin Chest Med 1994;15:1-12.

3. Freebairn RC, Derrick J, Gomersall CD, Young RJ, Joynt GM. Oxygen delivery, oxygen consumption, and gastric intramucosal
$\mathrm{pH}$ are not improved by a computer-controlled, closed-loop, vecuronium infusion in severe sepsis and septic shock. Crit Care Med 1997;25:72-7.

4. Bruder N, Lassegue D, Pelissier D, Graziani N, Francois G. Energy expenditure and withdrawal of sedation in severe head-injured patients. Crit Care Med 1994;22:1114-9.

5. Godet G, Gossens S, Prayssac P, Daghfous M, Delbrouck D, Aigret $D$, et al. Infusionof propofol, sufentanil, or midazolam forsedation after surgery: Comparison of oxygen consumption and hemodynamic stability. Anesth Analg 1998;87:272-6.

6. McCall M, Jeejeebhoy K, Pencharz P, Moulton R. Effect of neuromuscular blockade on energy expenditure in patients with severe head injury. JPEN 2003;27:27-35.

7. MacDonald A, Hildebrant L. Comparison of formulaic equations to determine energy expenditure in the critically ill patient. Nutrition 2003:19:233-9.

8. Schneider G, Heglmeier S, Schneider J, Tempel G, Kochs EF. Patient state index (PSI) measures depth of sedation in intensive care patients. Intensive Care Med 2004;30:213-6.

9. Cunningham JJ. Calculation of energy expenditure from indirect calorimetry: assessment of the Weir equation. Nutrition 1990;6:222-3.

10. Headley JM. Indirect calorimetry: a trend toward continuous metabolic assessment. AACN Clin Issues 2003;14:155-67.

11. Vernon DD, Witte MK. Effect of neuromuscular blockade on oxygen consumption and energy expenditure in sedated, mechanically ventilated children. Crit Care Med 2000;28:1569-71.

12. Marik PE, Kaufman D. The effects of neuromuscular paralysis on systemic and splanchnic oxygen utilization in mechanically ventilated patients. Chest 1996;109: 1038-1042

13. Manthous CA, Hall JB, Kushner R, Schmidt GA, Russo G, Wood L. The effect of mechanical ventilation on oxygen consumption in critically ill patients. Am J Respir Crit Care Med 1995;151:210-4.

14. Russell WC, Greer R, Harper NJN. The effect of neuromuscular bkockade on oxygen supply, consumption, and total chest compliance in patients with high oxygen requirements undergoing mechanical ventilation. Anaesth Intensive Care 2002;30:192-7.

15. Bruder N, Raynal M, Pellissier D, Courtinat C, Francois G. Influence of body temperature, with or without sedation, on energy expenditure in severe head-injured patients. Crit Care Med 1998;26:568-72.

16. Swinamer DL, Phang PT, Jones RL, Grace M, King EG. Effect of routine administration of analgesia on energy expenditure in critically ill patients. Chest 1988;93:4-10.

17. Gebara BM, Gelmini M, Sarnaik A. Oxygen consumption, energy expenditure, and substrate utilization after cardiac surgery in children. Crit Care Med 1992;20:1550-4. 